\title{
Percepção de pacientes oncológicos infanto- juvenis, profissionais de saúde e familiares sobre o adoecimento - revisão sistemática
}

\author{
Perception of childhood and youth oncological \\ patients, healthcare professionals and families \\ about the disease - systematic review
}

\section{Íris Borges Brito Mota' ${ }^{1}$ Alena Peixoto Medrado (1)}

\author{
Escola Bahiana de Medicina e Saúde Pública (Salvador). Bahia, Brasil. irisborges_1988@hotmail.com \\ ${ }^{2}$ Autora para correspondência. Escola Bahiana de Medicina e Saúde Pública (Salvador). Bahia, Brasil. alenamedrado@hotmail.com
}

\begin{abstract}
RESUMO | Compreender o real significado do universo de sentimentos vivenciados pelo paciente oncológico pediátrico-juvenil torna-se um desafio para a equipe multidisciplinar em saúde. Este estudo objetivou proporcionar um melhor entendimento sobre a forma como as crianças e adolescentes com câncer compreendem a doença, o cuidado por parte dos profissionais de saúde, a convivência com a equipe hospitalar e a sua relação com os familiares envolvidos neste processo. Tratou-se de uma revisão sistemática da literatura que incluiu estudos qualiquantitativos publicados entre 2014 e 2018, em inglês e português, os quais foram selecionados a partir das bases de dados PUBMED, Scielo, BDENF. Um total de 599 artigos foram encontrados, dos quais 5 foram selecionados por atenderem aos critérios de inclusão estabelecidos. Observou-se que todos os estudos foram realizados em seres humanos, contemplando 281 crianças, adolescentes, seus pais e profissionais de saúde, abordando suas percepções e experiências durante o tratamento do câncer. Constatou-se que o diagnóstico do câncer repercute de maneira diferenciada para cada paciente e via de regra, relaciona-se a sentimentos negativos, como medo, ansiedade e depressão. O maior desafio citado pelos pacientes foi a sua reintegração às atividades cotidianas. Foi relatado pelos pais e profissionais de saúde que as crianças apresentam alto grau de sofrimento, o qual é compartilhado pela família, cuidadores e profissionais de saúde. A realização deste estudo possibilitou uma melhor compreensão do cotidiano destas crianças e adolescentes, a forma como elas se relacionam com os profissionais de saúde e com sua família.
\end{abstract}

PALAVRAS-CHAVE: Neoplasia. Paciente pediátrico. Percepção. Adolescente.

\begin{abstract}
The understanding of the real meaning of the universe of feelings experienced by pediatric-juvenile cancer patients representes a challenge for the multidisciplinary health team. This study aimed to provide a better understanding of how children and adolescents with cancer understand the disease, the care by health professionals, the experience of living at hospital team and their relationship with family members involved in this process. It was a systematic review that included qualitative and quantitative studies published between 2014 and 2018, in English and Portuguese, which were selected from the PUBMED, Scielo, BDENF databases. A total of 599 articles were found and 5 were selected because they met the established inclusion criteria. It was observed that all studies were carried out in human beings, covering 281 children, adolescents, their parents and health professionals, addressing their perceptions and experiences during the treatment of cancer. It was found that the diagnosis of cancer has a different impact on each patient and, as a rule, is related to negative feelings, such as fear, anxiety and depression. The biggest challenge cited by patients was their reintegration into daily activities. It was reported by parents and health professionals that children have a high degree of suffering, which is shared by family, caregivers and health professionals. The realization of this study enabled a better understanding of the daily lives of these children and adolescents, the way they relate to health professionals and their families.
\end{abstract}

KEYWORDS: Neoplasia. Pediatric patient. Perception. Teenager. 


\section{Introdução}

O câncer corresponde a um grupo de várias doenças que têm em comum a proliferação descontrolada de células anormais e que pode ocorrer em qualquer local do organismo. Os tumores mais frequentes na infância e na adolescência são os linfomas, aqueles que afetam o sistema nervoso central e as leucemias que atingem a medula óssea. Assim como em países desenvolvidos, no Brasil, o câncer já representa uma das primeiras causa de morte entre crianças e adolescentes de 1 a 19 anos e corresponde a $8 \%$ do total de óbitosin.

Do ponto de vista clínico, os tumores pediátricos apresentam menores períodos de latência. Em geral, crescem rapidamente e são mais invasivos, embora respondam melhor ao tratamento. No Brasil, nas últimas quatro décadas, o progresso no tratamento do câncer na infância e adolescência foi extremamente significativo. Segundo o INCA, em torno de $80 \%$ das crianças e adolescentes acometidas por câncer podem ser curados, quando diagnosticados precocemente e tratados em centros especializados. A maioria terá boa qualidade de vida após o tratamento adequado円.

O câncer, além de ser uma enfermidade crônica que ameaça a vida, simboliza o desconhecido, o perigoso, o sofrimento, a dor e a culpa. Quando a pessoa que adoece é uma criança, todas estas reações emocionais podem ser mais intensas para o pequeno paciente, e se estendem à famílial.

Com o aumento do número de sobreviventes, enfatiza-se um novo olhar no cuidado de pacientes da oncologia pediátrica e de suas famílias, baseado em uma abordagem multiprofissional que inclui serviços de apoio psicossocial desde o diagnóstico até o período pós-tratamento, com o objetivo de assegurar uma meIhor qualidade de vida com o mínimo de sequelas físicas e emocionaisf. Estima-se que a maioria das crianças que chega ao hospital não está preparada para enfrentar a doença e tudo que dela deriva. Em certos casos, ela será separada da família para entrar no contexto de uma instituição que passará a fazer parte de sua vida. Aparecerão personagens novos com os quais ela passará a estabelecer relações bastante duradouras, os profissionais de saúde. Vivenciará a quebra do seu ritmo de vida, necessitando de estratégias de enfrentamento para lidar com estas situações]. A hospitalização pediátrica vem sendo alvo de pesquisa nas últimas décadas e existem evidências que a descrevem como um evento potencialmente marcante para a criança/adolescente e sua famílial. A criança hospitalizada passa por diversos fatores estressores, que podem afetá-la emocionalmente.

Nota-se que esse tema ainda apresenta limitações na literatura, devido à escassez de estudos que abordem a percepção dos profissionais e da criança sobre o adoecimento e a família, bem como a construção de um elo entre os mesmos. Sentimentos diversos podem influenciar o tratamento desses pacientes oncológicos, entre os quais se destacam o medo do desconhecido, a dificuldade no ajustamento para com a sociedade, a angústia pela necessidade de passar por diversos procedimentos dolorosos, a ansiedade e a esperança pela cura, a saudade de casa, da família, dos amigos, da escola e da vida que tinham antes do diagnóstico, apesar de serem vivenciados também pelas pessoas mais próximas, assumem uma magnitude única no universo do paciente oncológico infantil.

Desse modo, o objetivo desta revisão sistemática qualitativa é descrever a percepção de pacientes oncológicos pediátricos, dos familiares e dos profissionais de saúde sobre o tratamento oncológico. 


\section{Materiais e métodos}

Tratou-se de um estudo de revisão sistemática qualitativa, que é um tipo de investigação que apresenta uma questão norteadora bem definida e tem o intuito de identificar, selecionar, avaliar e sintetizar o conteúdo disponível na literatura. Esse estudo foi instituído a metodologia Preferred Reporting Items for Systematic Reviews and Meta-Analyses (PRISMA) e o anagrama $\mathrm{PICO}$, no qual informações sobre a população (pacientes, profissionais de saúde e familiares), a intervenção (experiência do adoecimento com câncer) e o contexto (Unidades de tratamento de câncer infantil) foram coletadas em cada estudo selecionado.

Para a seleção dos artigos sobre a temática escolhi$\mathrm{da}$, foram realizadas as buscas nas bases de dados LILACS, BDENF e Medline, através da Biblioteca Virtual de Saúde (BVS). Os descritores selecionados, para a realização da pesquisa, foram encontrados através da consulta dos Descritores em Ciências da Saúde (DeCS), definindo-se como unitermos: paciente pediátrico; câncer; percepção; adolescente e seus respectivos termos correspondentes na língua inglesa, pediatric patients; cancer; percerption; understanding. A estratégia de busca utilizada incluiu os descritores com o uso do operador booleano "and".
Dois autores analisaram individualmente os resumos dos artigos para verificar quais estudos eram pertinentes ao tema desta revisão sistemática. Os critérios de inclusão para a seleção dos artigos científicos foram manuscritos científicos publicados em português e inglês, compreendendo os anos de 2008 a 2018 e que tivessem texto completo disponível. Foram incluídos no estudo apenas os artigos que apresentassem proximidade com a seguinte pergunta central: Qual a percepção dos pacientes oncológicos pediátricos sobre o adoecimento e sua relação com os profissionais de saúde? Artigos publicados em outros idiomas e anteriores ao período estabelecido não foram incluídos no estudo.

Após a consulta às bases de dados e a aplicação das estratégias de busca, bem como o uso dos critérios de inclusão e não inclusão, buscou-se identificar artigos duplicados. Posteriormente foram iniciadas as leituras dos resumos e, após a seleção dos trabalhos por meio dos resumos, foi realizada a sua leitura integral para determinar a elegibilidade do estudo. Foi elaborado um fluxograma com as descrições dos processos de identificação e seleção dos artigos pesquisados, subdividido nos seguintes tópicos: identificação, triagem, elegibilidade e estudos incluídos. Um total de 05 artigos foram incluídos nesta revisão sistemática (Figura 1). 
Figura 1. Fluxograma para seleção dos estudos encontrados. Salvador-BA, Brasil. Março de 2019
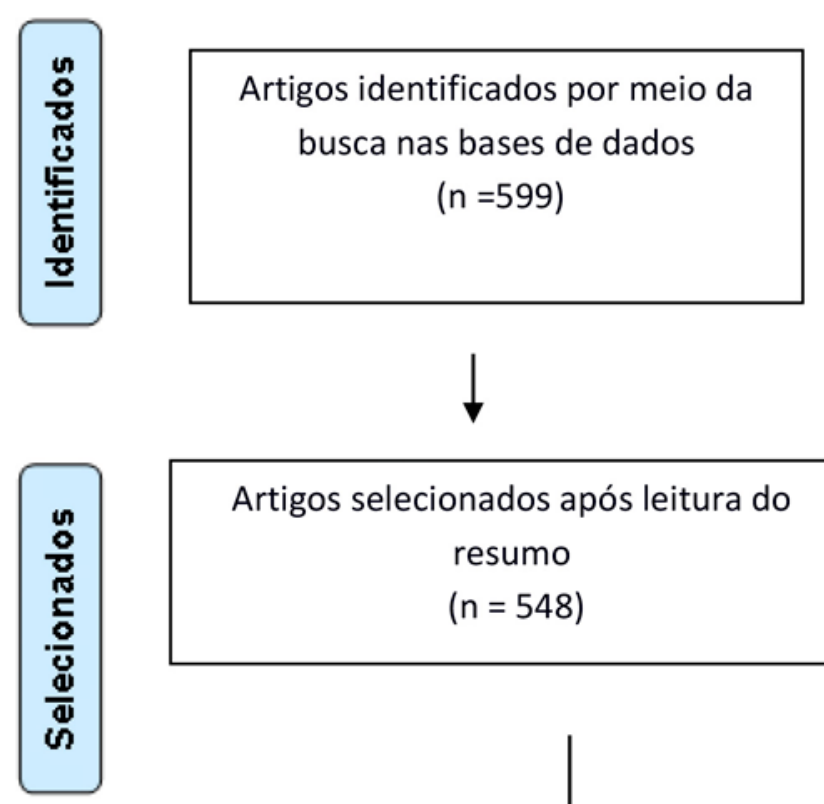

Artigos selecionados após leitura do resumo

$(n=548)$

Artigos adicionais em outras fontes

$$
(n=0)
$$

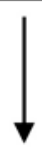

Artigos excluídos segundo os critérios de inclusão e não inclusão ( $n=542$ )

\begin{tabular}{|c|c|}
$\begin{array}{c}\text { Artigos completos } \\
\text { acessados e elegíveis } \\
(\mathrm{n}=06)\end{array}$ & $\begin{array}{c}\text { Artigo excluído por } \\
\text { não descrever a } \\
\text { metodologia } \\
(\mathrm{n}=01)\end{array}$ \\
\hline
\end{tabular}

$$
(n=05)
$$


Foi elaborada também uma tabela para avaliação dos estudos selecionados e extração de dados, a qual abrangeu as seguintes características dos manuscritos: autores, publicação, escore, participantes (grupo de indivíduos incluídos na pesquisa); intervenção (experiência vivenciada); desfecho clínico (descrição das variáveis de efetividade e segurança dos pacientes e dos profissionais de saúde que lidam com eles) e o tipo e desenho de estudo.

Os resultados foram comparados e em caso de um desacordo foi discutido pelos avaliadores. Não havendo consenso com relação ao nível de evidência científica ou da qualidade do ensaio clínico de um determinado estudo, um terceiro avaliador foi incluído na avaliação destes aspectos.

\section{Resultados}

De acordo com a tabela 1, foram encontrados nas bases de dados selecionadas um total de 599 (quinhentos e noventa e nove) publicações com os descritores escolhidos.

Tabela 1. Número de estudos identificados nas bases de dados ( $n=599)$ para a realização da revisão sistemática. Salvador-BA, Brasil. Março de 2019

\begin{tabular}{cc}
\hline Base de Dados & $\mathbf{N}^{\circ}$ de estudos (n=599) \\
\hline Lilacs & 03 \\
Scielo & 585 \\
MedLine & 585 \\
\hline
\end{tabular}

Fonte: As autoras (2020).

Dos cinco estudos selecionados, 04 foram internacionais, sendo 02 estudos descritivos e qualitativos, 01 de teste clínico e 01 multi-institucional. As amostras dos estudos apresentaram tamanho variável, sendo a menor constituída por 11 indivíduos e a maior por 129 pacientes. O número total de particpantes nos estudos foi de 292.

Os dados extraídos dos artigos selecionados acham-se descritos na tabela 2. 


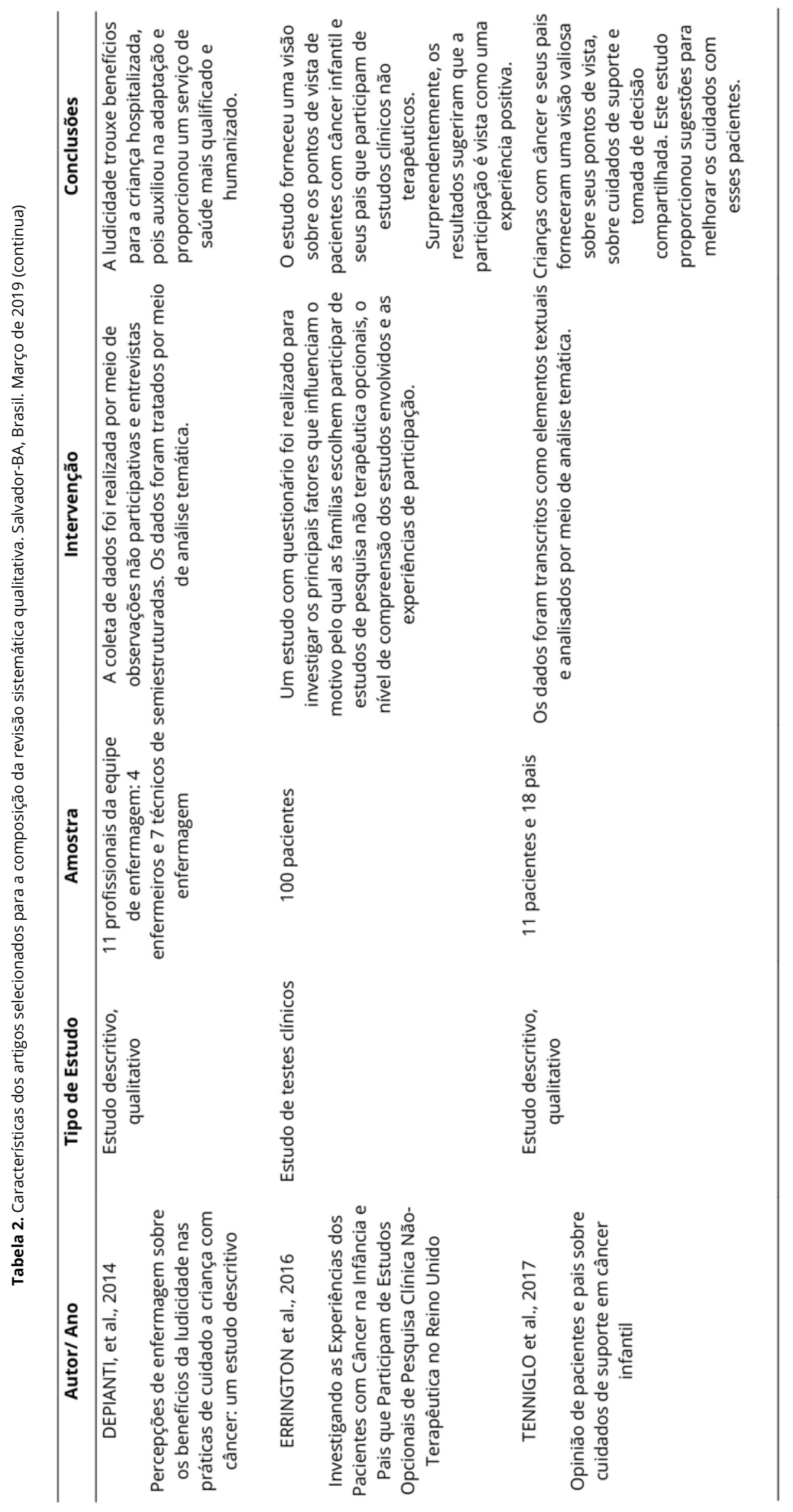




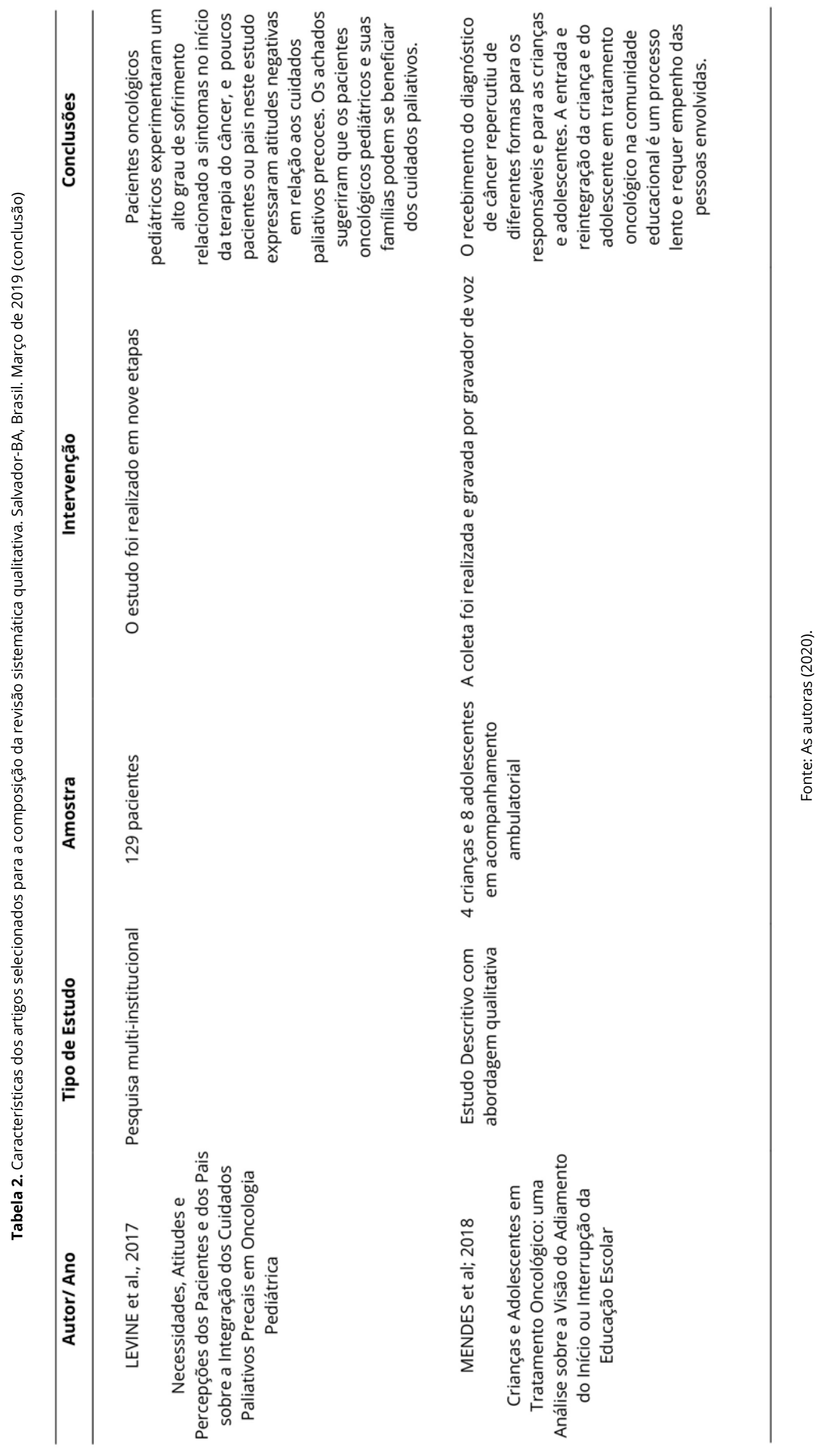


Dos artigos selecionados, 03 corresponderam à percepção de pacientes pediátricos e adolescentes com câncer, e seus familiares, e 02 avaliaram o sentimento dos profissionais de saúde no tocante a realidade de vida de seus pacientes.

Nos estudos qualitativos, foi comum observar relatos e depoimentos dos pacientes pediátricos e de seus familiares que evidenciaram sentimentos negativos como tristeza, medo, ansiedade e depressão. Da mesma forma, o enfrentamento do convívio com tais pacientes foi descrito como desafiador, conforme destacam os relatos dos enfermeiros descritos a seguir. Assim como foi destacado pelos sujeitos, o lúdico expresso por meio de brinquedos e estórias é um instrumento que auxilia no cuidado à criança com câncer hospitalizada, pois atua facilitando sua adaptação e sua aceitação aos procedimentos. Além disso, ameniza a dor, aumenta sua compreensão em relação ao tratamento e facilita o vínculo entre ela e o profissional, bem como aumenta a confiança da criança e da família na equipe que está realizando os cuidados. Desses relatos acham-se transcritos:

"Eles compreendem o que tem que ser feito, entendem e aceitam melhor o procedimento (Adedonha).'

"Faz com que a criança tenha confiança. Ela obtém confiança através dos brinquedos (Amarelinha).' '†

"As crianças aceitam melhor, às vezes você contando uma estória, criando uma estória em cima do procedimento que vai ser feito (...) ela aceita melhor do que simplesmente chegar e impor (Queimada).'

"Ela se adapta mais ao ambiente, ameniza a dor, consegue se sentir um pouco mais a vontade (...) faz com que ela sinta que você é amiga e gosta dela (Ciranda).'甲

"O uso do lúdico otimiza o trabalho (...) porque melhora a colaboração da criança e participação da mãe (...); tem mais envolvimento tanto da enfermagem, como da mãe que acompanha a criança e da própria criança (Esconde-Esconde).'1

"Acho importante tentar trazer a criança para o nosso lado, porque o mundo da criança é muito fantasioso (...), contar estória é uma forma fácil de trazer a criança até nós e facilitar o trabalho (Cabra-Cega).' ']
"O benefício é para a gente e para ela, porque é muito ruim a gente tratar de uma criança que tem leucemia, porque a criança fica enjoada, quando ela está com dor, é um meio mais fácil da gente chegar (Pique).'१

O sentimento das crianças também destacou-se nos estudos catalogados e algumas das declarações acham-se transcritas a seguir:

"Para mim, foi normal [receber o diagnóstico]. Foi um pouco mais complicada [mudar a rotina]. Tinha que acordar mais cedo que o normal. Eu já estava acostumada com a rotina do colégio que era seis em ponto agora eu tenho que acordar mais cedo para poder chegar aqui" (a1. 12 anos. idade do diagnóstico 12 anos)

"Eu digo que a vida deu um nó, virou de cabeça pra baixo. No começo, foi um pouco difícil. Antes eu estudava, como eu moro na área rural, ajudava

a trabalhar com meus pais e tinha uma rotina bastante esportiva." (a2. 16 anos. idade do diagnóstico 14 anos) 11.

"Foi difícil. Mas depois fui me costumando eu fazia quimioterapia, tomava remédio, ia para a consulta. Antes eu vinha todo dia, agora eu venho uma vez na semana. Antes era ruim, porque todo dia eu tinha que pegar acesso todo dia, né?" (c1. 8 anos. idade do diagnóstico 7 anos)

\section{Discussão}

A presente revisão buscou enfatizar o olhar no cuidado dos pacientes oncológicos infanto-juvenis, abordando a percepção dos pacientes, cuidadores e profissionais de saúde. Ao realizar a pesquisa bibliográfica foi identificada escassez de artigos relacionados com a percepção desses pacientes e pessoas envolvidas no cuidado e/ou convivência. Assim, houve dificuldade na coleta de artigos que se enquadrassem na pergunta central do trabalho.

Embora existam relatos por parte de autores que investigaram os sentimentos, atitudes e nível de compreensão do câncer infanto-juvenil na visão dos cuidadores, genitores e em especial, dos profissionais que integram a equipe multiprofissional de sáude, 
percebeu-se que o principal personagem que vivencia esta realidade, a criança e/ou o jovem, apresenta reflexões dignas de nota que precisam ser mais conhecidas no universo da literatura científica :"A minha rotina mudou pouca coisa, mas atingiu mais a rotina dos meus pais. Sempre os vejo conversando e acho desgastante... [pausa]. Às vezes,eu só queria que fosse a última vez a ir ao hospital(A8. 16 anos. Idade do diagnóstico 15 anos)" "1. A hospitalização provoca alterações na rotina das crianças e de suas famílias, e elas precisam se adaptar à essa nova e desafiadora realidade 7 . Normalmente, este processo gera um distanciamento de parentes, colegas e de sua rotina habitual. Na criança, provoca alterações comportamentais e emocionais, fazendo com que se sintam inseguras, ansiosas e temerosas no novo ambiente. Desta forma, conhecer de perto os sentimentos desta população por parte da equipe multidisciplinar em saúde assume grande relevância, pois pode contribuir para o estabelecimento de um vínculo de confiança mais forte e duradouro entre os pacientes e seus cuidadores e entre estes e os profissionais de saúde.

Adicionalmente, os pacientes que vivenciam o processo de adoecimento, preocupam-se com os pais, em face da modificação da vida destes em razão do seu tratamento"1]. Tais autores ressaltam que, em face destas mudanças, as crianças e os adolescentes são forçados a enfrentar uma rotina com novas regras, bem como vivenciar o processo terapêutico recomendado, além de ter que aprender a lidar com suas vontades e desejos não satisfeitos. Neste estudo, foi evidenciada a preocupação destes pacientes com os seus genitores e/ou cuidadores, pois muitas vezes estes também compartilham o vivenciamento da difícil realidade enfrentada pelas crianças e adolescentes com câncer.

Na presente revisão sistemática, observou-se que 4 dos estudos selecionados relataram a percepçãos dos pacientes pediátricos acerca do câncer. Pelo menos 3 destes, também investigaram o sentimento dos pais e/ou cuidadores: A ludicidade trouxe benefícios para a criança hospitalizada, pois auxiliou na adaptação e proporcionou um serviço de saúde mais qualificado e humanizado]. O estudo forneceu uma visão sobre os pontos de vista de pacientes com câncer infantil e seus pais que participam de estudos clínicos não terapêuticos. Surpreendentemente, os resultados sugeriram que a participação é vista como uma experiência positiva . Crianças com câncer e seus pais forneceram uma visão valiosa sobre seus pontos de vista, sobre cuidados de suporte e tomada de decisão compartilhada. Este estudo proporcionou sugestões para melhorar os cuidados com esses pacientes?. É digno de nota que diante das mudanças em relação à rotina do paciente em tratamento, sentimentos de incerteza e apreensão dominem o universo de emoções dos responsáveis. Contudo, através da leitura dos artigos selecionados, percebeu-se a premente necessidade por parte desta população, de assegurar ao menor sob tratamento, o constante apoio e enfrentamento da doença com positividade. Ambos os grupos, pais e pacientes, sempre apresentaram uma forte disposição de cooperar com a equipe multidisciplinar em saúde e experimentar novas estratégias terapêuticas, fortalecendo o sentimento de esperança por ambas as partes. A perspectiva da finitude da vida exerce um grande impacto tanto no paciente pediátrico quanto no seu responsável e muitas vezes é comum o estabelecimento de uma ambiente de tristeza e negatividade. Sendo assim, diante da constância do desafio de vivenciar no seu cotidiano esta realidade que lhes é imposta, urge a necessidade de desenvolver estratégias de enfrentamento da doença que permitam suavizar a experiência do adoecimento.

Os profissionais de saúde exercem um papel fundamental antes, durante e após o tratamento oncológico, pois criam vínculos duradouros de amizade e companheirismo com os pacientes e familiares. De fato, o profissional de saúde que assite a criança e o adolescente com câncer, se torna o novo 'personagem' e o seu maior desafio é conseguir a confiança desses pacientes e construir relações que possam atenuar a dinâmica do tratamento. $O$ uso da linguagem lúdica, representou um recurso eficiente para a melhora da adaptação da criança ao ambiente hospitalar, e facilitou a interação social do paciente com a equipe de enfermagem e com os acompanhantes ${ }^{7}$. Por meio da ludicidade, os profissionais encontram alternativas para abordar a criança, como contar histórias, e então descobriram que foram capazes de animar os pacientes e seus cuidadores de modo a contribuir na rotina de trabalho. $O$ apoio de toda a equipe de saúde multidisciplinar, bem como o da família e da sociedade, é essencial nesse momento, pois o enfrentamento dessa nova realidade reflete uma ruptura do processo infantojuvenil natural1. 
O apoio prestado por médicos, enfermeiros e assistentes sociais por meio de conversas animadoras e positivas, além do contato direto dos profissionais com estes pacientes, através de um olhar, um aperto de mãos e/ou um abraço, se constituíram elementos de grande importância para a construção de um ambiente fraterno no qual esta empatia propiciou o desenvolvimento de confiança e afetividade entre o paciente e a equipe multidisciplinar de saúde. $O$ autor também abordou a relevância da tomada de decisão compartilhada dos profissionais com os pais e/ou responsáveis no tocante à modalidade de tratamento oncológicol.

Outro aspecto importante destacado nos estudos compilados nesta revisão sistemática foi salientado, concernente à percepção dos pacientes oncológicos infanto-juvenis sobre os cuidados paliativos" Os autores relataram que a maior parte dos pacientes e/ou pais e responsáveis que participaram do estudo não se opuseram ao cuidado paliativo inicial ou expressaram uma atitude negativa frente a estes recursos terapêuticos. De fato, foi evidenciado que a utilização de recursos paliativos pode melhorar o bem-estar físico e emocional dos pacientes, bem como sua qualidade de vida durante o curso da terapia e após o término desta.

Ao avaliarem a participação desta população em ensaios clínicos não terapêuticos, observaram que a colaboração foi vista como uma experiência positiva8. Um dos aspectos destacados pelos autores foi de que a participação no estudo esteve relacionada ao desejo de ajudar a gerar informações que pudessem direcionar a tratamentos mais acertivos para futuros pacientes com câncer infantil. Este interesse em colaborar no desenvolvimento de novas estratégias de tratamento reflete a preocupação com o processo de adoecimento, bem como com a possibilidade de cura, ainda que remota, por parte dos pacientes e/ou seus pais e responsáveis.

\section{Conclusão}

O engajamento da equipe multiprofissional é de suma importância para a abordagem desta população, desde o diagnóstico inicial da doença, onde o paciente e sua família atravessam as fases de negação, frustração, revolta e aceitamento até o desenrolar do tratamento e o término deste. E vale ressaltar a importância do cirugião-dentista que estiver capacitado para o atendimento ao paciente oncológico, ao recebê-lo antes do início das terapias. Diversas alterações bucais decorrentes do tratamento e não da doença em si podem acometer o indivíduo com câncer. O tratamento não cirúrgico do câncer é feito por meio da quimioterapia, da radioterapia, da radioiodoterapia etc., de maneira isolada ou associada. Elas provocam manifestações orais graves como mucosite, xerostomia, infecção bacteriana, fúngica e viral. As manifestações orais do tratamento do câncer se instalam sucessivamente em cadeia, se agravando, pois o mecanismo de ação citotóxica das drogas confere indistintamente a paralização do crescimento celular. E diante da baixa imunidade favorece o crescimento bacteriano, viral e fúngico, promove a quebra da homeostase bucal, ocasionada ainda pela diminuição de fluxo salivar. Diante da multiplicidade de sinais e sintomas, modalidades terapêuticas por vezes invasivas e dolorosas, assim como de sentimentos vivenciados pelos pacientes oncológicos infanto-juvenis, compreender esta desafiadora realidade assume grande relevância a fim de proporcionar a implementação de cuidados em saúde mais integrais e humanizados.

\section{Agradecimentos}

As autoras agradecem a concessão de bolsa de Iniciação Científica para a realização deste estudo para a acadêmica Íris Borges Brito Mota, pela Fundação de Amparo à Pesquisa do Estado da Bahia (FAPESB).

\section{Contribuições das autoras}

Mota IBB realizou a busca bibliográfica desta revisão sistemática e participou da escrita do manuscrito. Medrado AP orientou a redação do manuscrito e contribuiu criticamente na discussão dos resultados. 


\section{Conflitos de interesses}

Nenhum conflito financeiro, legal ou político envolvendo terceiros (governo, empresas e fundações privadas, etc.) foi declarado para nenhum aspecto do trabalho submetido (incluindo, mas não se limitando a subvenções e financiamentos, participação em conselho consultivo, desenho de estudo, preparação de manuscrito, análise estatística, etc.).

\section{Referências}

1. Instituto Nacional do Câncer. Câncer - Tipo de Câncer - Infantil. Ministério da Saúde.[Internet]. 2016. [acesso em 2017 jun. 13]. Disponivel em: https://www.inca.gov.br/tipos-de-cancer/cancerinfantojuvenil

2. Instituto Nacional do Câncer. Câncer - Tipo de Câncer - Infantil. Ministério da Saúde. [Internet]. 2007. [acesso em 2018 out. 08]. Disponível em: https://www.inca.gov.br/tipos-de-cancer/cancerinfantojuvenil

3. Castillo E, Chelsa C. Viviendo com el câncer de um (a) hijo (a). Colomb Med. 2003;34:155-63.

4. Björk M, Wiebe T, Hallström I. Striving to survive: Families' lived experiences when a child is diagnosed with cancer. J Pediatr Oncol Nurs. 2005;22(5):265-75. doi: 10.1177/1043454205279303

5. Yantzi N, Rosenberg MW, Burke SO, Harrison MB. The impacts of distance to hospital on families with a child with a chronic condition. Soc Sci Med. 2001;52(12):1777-91. doi: 10.1016/s02779536(00)00297-5

6. Parcianello AT, Felin RB. E agora doutor, onde vou brincar? Considerações sobre a hospitalização infantil. Barbarói. 2008;28:147-166. doi: 10.17058/barbaroi.v0i0.356

7. Depianti JRB, Silva LF, Carvalho AS, Monteiro ACM. Nursing perceptions of the benefits of ludicity on care practices for children with cancer: a descriptive study. Online Braz J Nurs. 2014;13(2):158-65. doi: 10.5935/1676-4285.20144314

8. Errington J, Malik G, Evans J, Baston J, Parry A, Price L et al. Investigating the Experiences of Childhood Cancer Patients and Parents Participating in Optional Nontherapeutic Clinical Research Studies in the UK. Pediatr Blood Cancer. 2016; 63(7):1193-7. doi: $10.1002 / p b c .25960$

9. Tenniglo LJA, Loeffen EAH, Kremer LCM, Font-Gonzalez A, Mulder RL, Postma A et al. Patients' and parents' views regarding supportive care in childhood cancer. Support Care Cancer. 2017;25(10): 3151-3160. doi: 10.1007/s00520-017-3723-7
10. Levine DR, Mandrell BN, Sykes A, Pritchard M, Gibson D, Wendler D et al. Patients' and Parents' Needs, Attitudes, and Perceptions About Early Palliative Care Integration in Pediatric Oncology. JAMA Oncol. 2017;3(9):1214-1220. doi: 10.1001/ jamaoncol.2017.0368

11. Mendes MVC, Góes ACF, Brain FRM. Crianças e Adolescentes em Tratamento Oncológico: uma Análise sobre a Visão do Adiamento do Início ou Interrupção da Educação Escolar. Rev Bras de Cancerol. 2018;4(3):301-309. doi: 10.32635/2176-9745. RBC.2018v64n3.27 